\title{
Depressive Symptoms and Involvement in Physical Fighting among Portuguese Adolescents
}

\author{
Silvia Fraga, Elisabete Ramos, and Henrique Barros
}

\begin{abstract}
In this article, authors present findings on the relationship between depressive symptoms and involvement in physical fighting in late adolescence. Participants were 1,380 Portuguese adolescents initially recruited in 2003 to the EPITeen cohort. Depressive symptoms were assessed at 13 and 17 years of age using Beck Depressive Inventory II (BDI). Physical fighting was recorded at the age of 17 . For girls, there was a significant association between depressive symptoms and physical fighting for those who scored BDI $>13$ at 17 years old and remained statistically significant after adjustment. For boys, those who scored $>13$ in both study waves presented higher crude odds to engage in fights that were attenuated after adjusting for grade retention. Depressive symptoms were significantly related to physical fighting involvement during adolescence, for both genders. However, whereas for female adolescents the association was significant when relevant symptoms and fighting occurred in the same period, for male adolescents such symptoms must have persisted from 13 to 17 years of age.
\end{abstract}

KEY WORDS: adolescence; depression; mental health; violence

$\mathrm{P}$ hysical fighting involvement is usually disregarded, because it is considered a normal behavior in adolescence. However, this behavior is significantly correlated with other unhealthy critical behaviors in late adolescence such as smoking, drinking alcohol, and engaging in sexual risk behaviors (Fraga, Ramos, Dias, \& Barros, 2011). Physical fighting represents an aggressive behavior that puts young people at significant risk for harm (Pickett et al., 2005) and also may signal a lack of interpersonal skills.

Although violent behavior has been related with some psychopathology factors, it is not common to view depression as indicative of aggressive behavior. At first glance, this relationship seems paradoxical because the central components of depression are blaming oneself easily and becoming tired and exhausted, making a person too listless to aggress. However, feeling unhappy and sad or being pessimistic about the future are other significant symptoms of depression that could also make a person irritable, and therefore contribute to aggressive behavior toward others. This overlooking of depression as irritability and not as vegetative supports the link between depression and aggression. Both internalizing problems, which reflect an internal distress (for example, depression, anxiety), and externalizing problems, which bring the individual into conflict with others (for example, rule breaking, aggression), are shown to be considered in developmental pathways during adolescence (Colder et al., 2013). The cooccurrence of both internalizing and externalizing factors may be the result of genetic and environmental influences during adolescence (Cosgrove et al., 2011).

Also, with regard to the relationship of depression and interpersonal violence, some studies have reported increased likelihood of spouse abuse (Bland \& Orn, 1986), spousal homicide (Belfrage \& Rying, 2004), child abuse (Zuravin, 1989), and adolescents' proactive aggressiveness (Anderson et al., 2001; Cleary, 2000; Roland, 2002) in participants reporting depression. A potential explanation for these findings was that depression and violence may share some early factors, namely familial effects that may arise from genetic predisposition and environmental adversity. These factors may contribute to the development of traits such as impulsivity and mood instability, relevant as common causes of both depression and violence (Nestor, 2002). Nonetheless, a previous study showed that after adjustment for sociodemographic and familial factors, the diagnosis of 
depression modestly increased the risk of violence (Fazel et al., 2015), which could mean that this relationship may be partially independent of potential confounders.

There is limited empirical evidence for depression as a causal factor for aggression (Dutton \& Karakanta, 2013), and there is a lack of studies addressing the relationship between depressive symptoms and physical fighting, that is, a violent behavior in which adolescents are involved simultaneously as a victim and an aggressor. A previous study showed that depressive symptoms were a risk factor for future fight-related injury in girls but did not find such association in boys (Borowsky \& Ireland, 2004). However, that study was based on two evaluations separated by approximately one year, and only the baseline measurement of depressive symptoms was considered in the analysis. Thus, it did not allow for observation of the effect of persistence or remission of symptoms.

Besides other adolescents' behaviors that may affect the association between depression and violence, gender differences may be relevant to understand the mechanisms behind this potential association. First, the rates of physical fighting are higher among male adolescents and depressive symptoms tend to be more prevalent among female adolescents. Second, depression is expressed by the onset of feelings (Renouf \& Harter, 1990) that can be experienced differently by male and female adolescents. Expression of such feelings or emotions is culturally shaped (Waite, 2006; Wang, Lederman, Andrade, \& Gorenstein, 2008) and, therefore, gender may have a relevant role.

Depression is a common psychiatric disorder among adolescence (Costello, Mustillo, Erkanli, Keeler, \& Angold, 2003), and violence is a main causes related to morbidity and mortality in young people, thus the understanding of both internalizing and externalizing behaviors is of high importance.

Portugal is a country with relatively high rates of depression among the general population, although the rates among adolescents are in line with estimates for other countries (Bulhoes, Ramos, Lindert, Dias, \& Barros, 2013). Violent behaviors such as homicides, carrying weapons, and gunfights are not as common in Portugal as they might be in other contexts. However, the World Health Organization collaborative study-Health Behaviour in SchoolAged Children-showed that physical fighting and bullying are violent behaviors common in Portugal among adolescents (Chester et al., 2015; Pickett et al., 2005). Although these behaviors tend to have low visibility in society, they are expected to be related with depressive symptoms that are frequently unrecognized in this age group. However, previous studies on this relationship tended to be crosssectional, and the association remains unclear. This study, using a Portuguese cohort, aims to estimate the relationship between depressive symptoms and involvement in physical fighting in late adolescence by taking a prospective approach.

\section{METHOD}

\section{Participants and Procedures}

The study sample consisted of urban adolescents who participated in the Epidemiological Health Investigation of Teenagers in Porto (EPITeen). As previously reported (Araujo, Severo, \& Ramos, 2012; Ramos \& Barros, 2007), the assembling and the first evaluation of the cohort were performed during 2003-2004. All adolescents born in 1990 and enrolled at public and private schools in Porto, Portugal, were invited to participate; 2,160 agreed and provided information at least for part of the planned assessment (77.5 percent response rate) (Ramos \& Barros, 2007). The second wave of evaluation took place in the 2007-2008 school year, and we were able to reexamine 1,716 (79.4 percent) participants (Araujo et al., 2012). The parents and the adolescents received oral and written information describing the study purpose and design. Written informed consent was obtained from both parents and adolescents. The joint Ethical Committee of Hospital S. João and University of Porto Medical School approved the study protocol.

In the present study we considered only those participants with complete information for the depressive symptoms at both evaluations and data on physical fighting involvement. Thus our final sample comprised 1,380 adolescents (743 female and 637 male), with information at ages 13 and 17.

Participants excluded from the analysis because of missing information in the key variables tended to be male (52.2 percent versus 46.2 percent, $p=.008$ ) and presented higher prevalence of relevant depressive symptoms at baseline (Beck Depression Inventory II [BDI] score higher than 13: 16.6 percent versus 12.1 percent, $p=.009)$. However, there were no significant differences regarding parents' education ( $>12$ years of education: 25.9 percent versus 26.6 percent, $p=.627$ ) or physical fighting 
involvement at 17 years of age (31.6 percent versus 36.7 percent, $p=.097)$.

\section{Measures and Data Collection}

At both study waves, information on social and behavioral characteristics was collected using selfadministered questionnaires at ages 13 and 17 years.

Depressive symptoms were measured using the Portuguese validated version of BDI (Beck, Steer, $\&$ Brown, 1996), and a score cutoff of 13 was used to define the presence of relevant depressive symptoms (Coelho, Martins, \& Barros, 2002). We computed a new variable to describe depressive symptoms, combining information from the two evaluations according to the presence of relevant depressive symptoms: (a) never, (b) only at 13 years old, (c) only at 17 years old, (d) at 13 and 17 years old.

Information on physical fighting was obtained at the 17-years-old evaluation and was assessed by the following question: "During the past 12 months, how many times were you involved in a physical fight?" Closed-option answers ranged from never to 12 times or more, but for the analysis, physical fighting was classified as no or yes.

Parents' educational level was measured as the number of successfully completed years of formal schooling. In the analysis we classified adolescents on the basis of the parent with the highest educational level. Parental cohabiting was assessed during the cohort recruitment and adolescents were classified as living with both parents, living with only the father or the mother, or living with neither parent (other person).

Information on early and late adolescence collected from questionnaires was combined. This information included adolescent smoking initiation. Adolescents were classified as never smokers or, if they had experienced cigarette smoking, they were further classified in one of two categories: initiation after 13 years if they did not smoke at 13 but smoked at 17 years of age; or before 13 years, if they already reported smoking in the 13-year-old questionnaire. Regarding alcohol drinking, they were classified as never drinkers or if they were already drinking, they were classified as drinker but without history of drunkenness or drinker with history of drunkenness.

Grade retention was considered the number of times a student in a given grade level for a full school year remained at that same level for the subsequent school year.

Exercising was assessed at 13 and 17 years of age using this question: "Apart from school time, how frequently do you practice sports for at least 20 minutes?" but for analysis participants were grouped dichotomously as practicing sports or not practicing sports. Information of both study waves allowed for computing a variable that reported changing behavior.

\section{Statistical Analysis}

Data were analyzed separately for female and male participants. The chi-square test was used to test statistical associations between depressive symptoms and physical fighting involvement, and logistic regression was used to estimate the magnitude of the association (odds ratios, with 95 percent confidence intervals [OR, 95\% CI]). Adjusted OR with 95\% CI were calculated through three models: (1) adjusted for parental education, (2) adjusted for parental education and alcohol drinking, and (3) adjusted for parental education, alcohol drinking, and grade retention.

\section{RESULTS}

At 13 years of age, 130 (17.5 percent) female and 37 (5.8 percent) male participants presented relevant depressive symptoms. At the 17-years-old followup evaluation, 112 (15.1 percent) female and 40 (5.4 percent) male participants scored more than 13 on the BDI. Of those who scored $>13$ at 13 years old, 59 (35.1 percent, 46 female and 13 male) also scored $>13$ at 17 years of age (see Figure 1). In female participants, involvement in fights was more frequent among those who were depressed at 17 years of age, regardless of being depressed (26.1 percent) or not being depressed (31.8 percent) at 13 years of age (see Figure 1). In male participants, findings were similar, but involvement in fights was much more common among those who were also depressed at 13 years of age (76.9 percent) than among those who were only depressed at 17 years (55.6 percent) (see Figure 1).

In female participants, age at smoking initiation and alcohol use were associated with the expression of depressive symptoms, whereas in male participants we found a significant association of depression with grade retention and lower sport practice (see Table 1). We also found a higher proportion of smokers, drinkers (namely those who reported at 


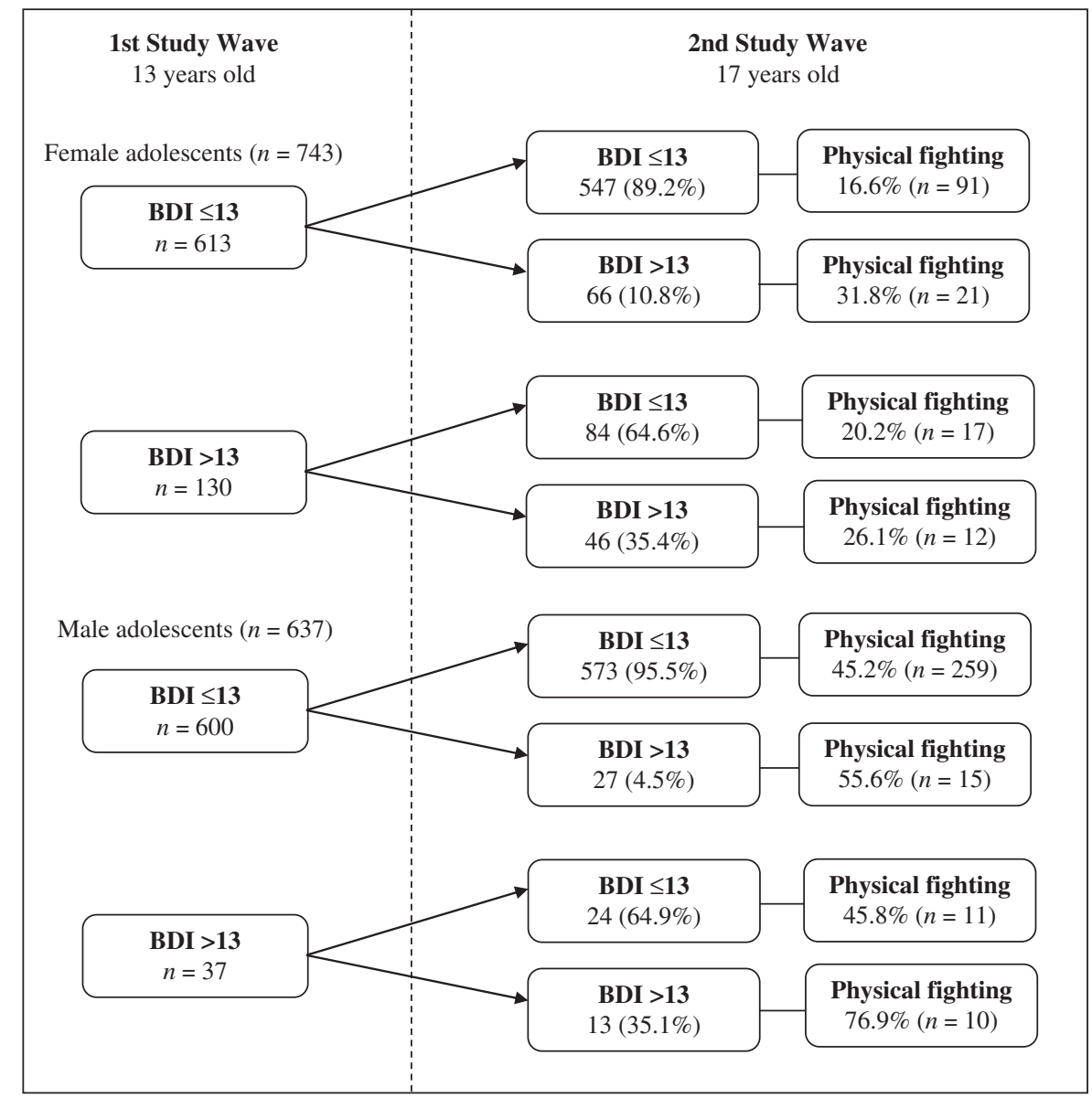

Note: $\mathrm{BDI}=$ Beck Depression Inventory II.

least one episode of drunkenness), and history of grade retention among adolescents involved in physical fighting (see Table 2).

In girls, relevant depressive symptoms only at 17 years of age were significantly associated with physical fighting $(O R=2.24$; 95\% CI: $1.33-4.11)$ and remained statistically significant after adjustment for alcohol drinking $(O R=2.13 ; 95 \% \mathrm{CI}$ : $1.20-3.79)$ and grade retention $(O R=2.55 ; 95 \%$ CI: 1.41-4.63). As shown in Table 3, boys who scored above 13 in both study waves presented higher odds to engage in fights when 17 years old $(O R=4.04 ; 95 \% \mathrm{CI}: 1.10-14.84)$ that remained statistically significant after adjustment for alcohol use $(O R=4.56$; $95 \% \mathrm{CI}: 1.21-17.14)$ but further attenuated when additionally adjusted for grade retention $(O R=3.34$; 95\% CI: 0.88-12.69).

Because we considered in the present analysis the involvement in fighting as yes or no in the last 12 months, we repeated the analysis considering physical fighting involvement as never or once versus two or more fights (data available on request). Results showed similar associations, although it attenuated the point estimates.

\section{DISCUSSION}

The present study showed that depressive symptoms were related to involvement in fighting. However, in girls the association was significant if relevant symptoms were expressed at 17 years of 
Table 1: Social and Behavioral Characteristics According to Depressive Symptoms, by Gender

\begin{tabular}{|c|c|c|c|c|c|c|c|c|c|c|}
\hline \multirow[b]{3}{*}{ Characteristic } & \multicolumn{5}{|c|}{ Female Adolescents } & \multicolumn{5}{|c|}{ Male Adolescents } \\
\hline & \multicolumn{5}{|c|}{ BDI $>13^{a}$} & \multicolumn{5}{|c|}{ BDI $>13^{a}$} \\
\hline & Never & $\begin{array}{l}\text { Only } \\
\text { at } 13 \\
\text { Years }\end{array}$ & $\begin{array}{l}\text { Only } \\
\text { at } 17 \\
\text { Years } \\
\end{array}$ & $\begin{array}{c}\text { Both } \\
13 \text { and } \\
17 \text { Years } \\
\end{array}$ & $\boldsymbol{p}$ & Never & $\begin{array}{l}\text { Only } \\
\text { at } 13 \\
\text { Years } \\
\end{array}$ & $\begin{array}{l}\text { Only } \\
\text { at } 17 \\
\text { Years } \\
\end{array}$ & $\begin{array}{c}\text { Both } \\
13 \text { and } \\
17 \text { Years }\end{array}$ & $\boldsymbol{p}$ \\
\hline \multicolumn{11}{|c|}{ Parents' education (years) } \\
\hline$<6$ & $149(27.3)$ & $34(40.5)$ & $16(24.2)$ & $10(22.2)$ & .164 & $136(23.7)$ & $11(45.8)$ & $9(5.7)$ & $3(1.9)$ & .381 \\
\hline $7-9$ & $110(20.2)$ & $20(23.8)$ & $13(19.7)$ & $10(22.2)$ & & $125(21.8)$ & $2(8.3)$ & $6(4.4)$ & $2(1.5)$ & \\
\hline $10-12$ & $147(27.0)$ & $19(22.6)$ & $17(25.8)$ & $11(24.4)$ & & $155(27.1)$ & $6(25.0)$ & $6(3.6)$ & $2(1.2)$ & \\
\hline$>12$ & $139(25.5)$ & $11(13.1)$ & $20(30.3)$ & $14(31.1)$ & & $157(27.4)$ & $5(20.8)$ & $6(3.5)$ & $5(2.9)$ & \\
\hline \multicolumn{11}{|l|}{ Parental cohabiting } \\
\hline Both parents & $392(74.2)$ & $61(72.6)$ & 39 (61.9) & $30(69.8)$ & .212 & $432(78.0)$ & $18(78.3)$ & $19(73.1)$ & $6(54.5)$ & .299 \\
\hline $\begin{array}{l}\text { Mother/ } \\
\text { father/other }\end{array}$ & $136(25.8)$ & $23(27.4)$ & $24(38.1)$ & $13(30.2)$ & & $122(22.0)$ & $5(21.7)$ & $7(26.9)$ & $5(45.5)$ & \\
\hline \multicolumn{11}{|l|}{ Grade retention } \\
\hline Never & $344(63.5)$ & $45(54.9)$ & $41(64.1)$ & $22(47.8)$ & .363 & $309(55.2)$ & $7(29.2)$ & $17(63.0)$ & $3(25.0)$ & .01 \\
\hline Once & $116(21.4)$ & $21(25.6)$ & $12(18.8)$ & $14(30.4)$ & & $136(24.3)$ & $8(33.3)$ & $3(11.1)$ & $7(58.3)$ & \\
\hline Twice or more & $82(15.1)$ & $16(19.5)$ & $11(17.2)$ & $10(21.7)$ & & $115(20.5)$ & $9(37.5)$ & 7 (25.9) & $2(16.7)$ & \\
\hline \multicolumn{11}{|l|}{ Smoking initiation } \\
\hline Never smoked & $279(51.1)$ & $34(40.5)$ & $27(40.9)$ & $19(41.3)$ & .045 & $274(48.0)$ & $9(37.5)$ & $12(44.4)$ & $5(41.7)$ & .243 \\
\hline After 13 years & $189(34.6)$ & $41(48.8)$ & $23(34.8)$ & $18(39.1)$ & & $184(32.2)$ & $9(37.5)$ & $12(44.4)$ & $7(59.3)$ & \\
\hline $\begin{array}{c}\text { Before } 13 \\
\text { years }\end{array}$ & $78(14.3)$ & $9(10.7)$ & $16(24.2)$ & $9(19.6)$ & & $113(19.8)$ & $6(25.0)$ & $3(11.1)$ & 0 & \\
\hline \multicolumn{11}{|l|}{ Alcohol drinking } \\
\hline Never & $100(18.3)$ & $17(20.2)$ & $6(9.1)$ & $7(15.2)$ & $<.001$ & 97 (16.9) & $3(12.5)$ & $5(19.2)$ & $4(36.4)$ & .327 \\
\hline Yes, but never & & & & & & & & & & \\
\hline drunk & $363(66.4)$ & $42(50.0)$ & $42(63.6)$ & $22(48.8)$ & & $317(55.3)$ & $17(70.8)$ & $13(50.0)$ & $3(27.3)$ & \\
\hline Yes, drunk & $84(15.4)$ & $25(29.8)$ & $18(27.3)$ & $17(11.8)$ & & $159(27.7)$ & $4(16.7)$ & $4(30.8)$ & $4(36.4)$ & \\
\hline \multicolumn{11}{|l|}{ Exercising } \\
\hline Never & $68(13.0)$ & $12(14.8)$ & $13(20.6)$ & $8(18.2)$ & .629 & $17(3.1)$ & 0 & $1(4.2)$ & 0 & .023 \\
\hline $\begin{array}{l}\text { Stopping } \\
\quad \text { before } 17 \\
\text { years }\end{array}$ & $93(17.7)$ & $14(17.3)$ & $11(17.5)$ & $9(20.5)$ & & $58(10.6)$ & $2(8.3)$ & $9(37.5)$ & $2(18.2)$ & \\
\hline $\begin{array}{l}\text { Starting at } \\
17 \text { years }\end{array}$ & $74(14.1)$ & $16(19.8)$ & $6(9.5)$ & 7 (15.9) & & $44(8.0)$ & $3(12.5)$ & $3(12.5)$ & $1(9.1)$ & \\
\hline $\begin{array}{l}\text { Remained } \\
\text { (13 years } \\
\text { and } 17 \text { years) }\end{array}$ & $289(55.2)$ & $39(48.1)$ & $33(52.4)$ & $20(45.5)$ & & $428(78.2)$ & $19(79.2)$ & $11(45.8)$ & $8(72.7)$ & \\
\hline
\end{tabular}

Notes: BDI = Beck Depression Inventory II. All values are $n$ or $(\%)$, unless otherwise indicated.

${ }^{\mathrm{a}}$ Beck Depressive Inventory II scoring higher than 13.

age, whereas in boys such association was statistically significant only if relevant symptoms were present at both ages (13 and 17 years).

Using two points in time of depressive symptoms, we could have a perspective of the history of depressive symptoms during adolescence, which was not possible to perform in the previous study (Borowsky \& Ireland, 2004) because there was only one assessment of depressive symptoms. Moreover, because we can assume that participants who score higher than 13 in BDI at both evaluations had a persistent depressive profile (Patten, Choi, Vickers,
\& Pierce, 2001), our results may underscore an important gender effect. In boys, relevant depressive symptoms persisted from age 13 to 17 years if the odds to be involved in physical fighting were higher, whereas in girls the association was statistically significant only when relevant symptoms were expressed at 17 years of age, regardless of the situation at 13 years of age. Our results allow to hypothesize that girls externalize more instantly their depressive feelings and therefore are immediately more reactive than boys and engage in fights, whereas in boys persistent depressive symptoms should be present for 


\begin{tabular}{|c|c|c|c|c|c|c|}
\hline \multirow[b]{3}{*}{ Characteristic } & \multirow{2}{*}{\multicolumn{3}{|c|}{$\begin{array}{c}\text { Female Adolescents } \\
\text { Physical Fighting }\end{array}$}} & \multirow{2}{*}{\multicolumn{3}{|c|}{$\begin{array}{c}\text { Male Adolescents } \\
\text { Physical Fighting }\end{array}$}} \\
\hline & & & & & & \\
\hline & $\begin{array}{c}\text { No } \\
n(\%)\end{array}$ & $\begin{array}{c}\text { Yes } \\
n(\%)\end{array}$ & $p$ & $\begin{array}{c}\text { No } \\
n(\%)\end{array}$ & $\begin{array}{c}\text { Yes } \\
n(\%)\end{array}$ & $\boldsymbol{p}$ \\
\hline \multicolumn{7}{|l|}{ Parents' education (years) } \\
\hline$<6$ & $158(26.4)$ & $51(36.2)$ & \multirow[t]{4}{*}{$<.001$} & $79(23.2)$ & $80(27.1)$ & \multirow[t]{4}{*}{.491} \\
\hline $7-9$ & $112(18.7)$ & $41(29.1)$ & & $70(20.5)$ & $65(22.0)$ & \\
\hline $10-12$ & $169(28.2)$ & $25(17.7)$ & & $92(27.0)$ & $77(26.1)$ & \\
\hline$>12$ & $160(26.7)$ & $24(17.0)$ & & $100(29.3)$ & $73(24.7)$ & \\
\hline \multicolumn{7}{|l|}{ Parental cohabiting } \\
\hline Both parents & $432(74.4)$ & $90(65.7)$ & \multirow[t]{2}{*}{.043} & $272(82.7)$ & $203(71.2)$ & \multirow[t]{2}{*}{.001} \\
\hline Mother/father/other & $149(25.6)$ & $47(34.3)$ & & $57(17.3)$ & $82(28.8)$ & \\
\hline \multicolumn{7}{|l|}{ Grade retention } \\
\hline Never & $396(66.8)$ & $56(39.7)$ & \multirow[t]{3}{*}{$<.001$} & $205(62.1)$ & $131(44.9)$ & \multirow[t]{3}{*}{$<.001$} \\
\hline Once & $127(21.4)$ & $36(25.5)$ & & $78(23.6)$ & $75(25.7)$ & \\
\hline Twice or more & $70(11.8)$ & $49(34.8)$ & & $47(14.2)$ & $86(29.5)$ & \\
\hline \multicolumn{7}{|l|}{ Smoking initiation } \\
\hline Never & $309(51.3)$ & $50(35.7)$ & \multirow[t]{3}{*}{.003} & $192(56.5)$ & $108(36.7)$ & \multirow[t]{3}{*}{$<.001$} \\
\hline After 13 years & $209(34.7)$ & $62(44.3)$ & & $87(25.6)$ & $125(42.5)$ & \\
\hline Before 13 years & $84(14.0)$ & $28(20.0)$ & & $61(17.9)$ & $61(20.7)$ & \\
\hline \multicolumn{7}{|l|}{ Alcohol drinking } \\
\hline Never & $123(20.4)$ & $7(5.0)$ & \multirow[t]{3}{*}{$<.001$} & $73(21.5)$ & $36(12.2)$ & \multirow[t]{3}{*}{$<.001$} \\
\hline Yes, but never drunk & $384(63.8)$ & $85(60.3)$ & & $198(58.2)$ & $152(51.7)$ & \\
\hline Yes, drunk & $95(15.8)$ & $49(34.8)$ & & $69(20.3)$ & $106(36.1)$ & \\
\hline \multicolumn{7}{|l|}{ Exercising } \\
\hline Never & $87(14.9)$ & $14(10.9)$ & \multirow[t]{4}{*}{.093} & $7(2.1)$ & $11(4.0)$ & \multirow[t]{4}{*}{.624} \\
\hline Stopping before 17 years & $109(18.7)$ & $18(14.0)$ & & $40(12.1)$ & $31(11.2)$ & \\
\hline Starting at 17 years & $88(15.1)$ & $15(11.6)$ & & $23(7.0)$ & $28(10.1)$ & \\
\hline Remained ( 13 years and 17 years) & $299(51.3)$ & $82(63.6)$ & & $260(78.8)$ & $206(74.6)$ & \\
\hline \multicolumn{7}{|l|}{$\mathrm{BDI}>13$} \\
\hline Never & $456(75.7)$ & $91(64.5)$ & \multirow[t]{4}{*}{.014} & $314(91.8)$ & $259(87.8)$ & \multirow[t]{4}{*}{.106} \\
\hline Only at 13 years & $67(11.1)$ & $17(12.1)$ & & $13(3.8)$ & $11(3.7)$ & \\
\hline Only at 17 years & $45(7.5)$ & $21(14.9)$ & & $12(3.5)$ & $15(5.1)$ & \\
\hline Both ages & $34(5.7)$ & $12(8.5)$ & & $3(0.9)$ & $10(3.4)$ & \\
\hline
\end{tabular}

Note: BDI = Beck Depression Inventory II.

\begin{tabular}{|c|c|c|c|c|}
\hline \multirow[b]{2}{*}{ BDI > 13 score } & \multicolumn{4}{|c|}{ Physical Fighting Involvement Odds Ratio (95\% Confidence Interval) } \\
\hline & Crude & Model 1 & Model 2 & Model 3 \\
\hline \multicolumn{5}{|l|}{ Female adolescents } \\
\hline Never & 1 & 1 & 1 & 1 \\
\hline Only at 13 years & $1.27(0.71-2.27)$ & $1.11(0.62-2.00)$ & $1.26(0.70-2.28)$ & $1.18(0.64-2.15)$ \\
\hline Only at 17 years & $2.34(1.33-4.11)$ & $2.47(1.39-4.40)$ & $2.13(1.20-3.79)$ & $2.55(1.41-4.63)$ \\
\hline Both ages & $1.77(0.88-3.55)$ & $1.89(0.93-3.85)$ & $1.58(0.77-3.25)$ & $1.52(0.73-3.13)$ \\
\hline \multicolumn{5}{|l|}{ Male adolescents } \\
\hline Never & 1 & 1 & 1 & 1 \\
\hline Only at 13 years & $1.03(0.45-2.33)$ & $0.99(0.43-2.26)$ & $0.95(0.41-2.23)$ & $0.80(0.34-1.86)$ \\
\hline Only at 17 years & $1.51(0.70-3.29)$ & $1.48(0.68-3.22)$ & $1.72(0.76-3.85)$ & $1.49(0.67-3.31)$ \\
\hline Both ages & $4.04(1.10-14.84)$ & $4.16(1.13-15.34)$ & $4.56(1.21-17.14)$ & $3.34(0.88-12.69)$ \\
\hline
\end{tabular}

Notes: BDI = Beck Depression Inventory Il; model 1: Adjusted for parents' education; model 2: Adjusted for parents' education and alcohol drinking; model 3: Adjusted for parents' education, alcohol drinking, and grade retention. 
this type of violent behavior to occur. An alternative explanation may be that girls with more persistent depressive mood are more socially withdrawn and isolated, resulting in fewer social encounters and therefore fewer opportunities for physical fighting. And probably in boys a persistent depressive profile can be associated with a different kind of profile.

With regard to depression symptoms, adolescents who felt depressed tended to experience anger or sadness, or even both (Renouf \& Harter, 1990). However, male and female adolescents have different ways of dealing with such feelings. It would be expected that male adolescents internalize their emotions, whereas female adolescents are more comfortable with externalizing theirs (Kim \& Capaldi, 2004; Renouf \& Harter, 1990). For that reason, gender could play an important role in the association between depression and fighting. However, it seems that if they directed anger toward the self (internalizing) or displayed this anger toward others (externalizing), they might eventually engage in violent behaviors such as fighting. We tested the association between each depressive symptom of the BDI instrument with fighting involvement and found similar associations among female and male adolescents (data available on request).

We should note that in physical fighting we cannot disentangle who is a victim or a perpetrator; it is assumed that each adolescent who reported physical fighting involvement assumed both roles, the victim and the perpetrator. Thus, the way we assessed physical fighting does not allow us to characterize who initiates the fight (adolescents may be involved in fights either on their own initiative or just responding to a provocation), the gender of the opponent, or the reason that the fight started. We cannot discard the possible differences in regard to the association of depressive symptoms and proactive and reactive fighting.

\section{Limitations}

Some methodological options should be pointed out. Our decision to analyze a single question to assess physical fighting involvement can be considered broad because it covers a set of behaviors and there are no specific victims or perpetrators identified. This question has been used by the Centers for Disease Control and Prevention (CDC) in the Youth Risk Behavior Surveillance System to monitor the prevalence of youth behaviors that most influence health (CDC, 1992), and it was also adopted in the cross-national survey Health Behavior in School-Aged Children developed by World Health Organization (Pickett et al., 2005, 2013). It is an easy question to use on the assessment, which tends to work well among young people, and allows the characterization of young people's behavior. We should note that during childhood this behavior is fairly common, probably representing a lower control of feelings by children compared with younger people. Although persistent fighting in childhood can be a serious problem, it is a way for children to test power or get attention, whereas in late adolescence involvement in fighting may reveal a conduct disorder or a negative approach to conflicts.

In our study, we addressed depressive symptoms based on the score of BDI (Beck et al., 1996) and not on a clinical diagnosis of depression. However, $\mathrm{BDI}$ is considered an adequate measure of depressive symptoms among adolescents for community-based surveys (Coelho et al., 2002). Our study was population based; therefore, the resulting scores of depressive symptoms were expectedly lower than the clinical samples, to some extent limiting statistical power because the number of participants who scored more than 13 was relatively small. We have considered as relevant symptoms when participants scored higher than 13 on the BDI, which is more consistent with mild symptoms of depression. Nevertheless, we found a positive association between depression and physical fighting that leads us to speculate that in a population with increasing risk of symptoms, the association would be even stronger. Also, we do not know whether depression at 13 years is associated with physical fighting at 13 years because physical fighting at 13 years was not assessed. It would be expected that depressive symptoms were already associated with physical fighting at 13 years among female adolescents but not among male adolescents.

Adjusted point estimates for the associations between depressive symptoms and physical fighting involvement were weaker than the crude ones but the global results were consistent, even facing a low prevalence of depressive symptoms among male adolescents and a low prevalence of physical fighting among female adolescents.

\section{Practice Implications}

Adolescent mental health and violence are major public health priorities. Our results support the relationship between fighting and mild depressive symptoms in 
adolescents, showing the relevance of its early identification. These results underline the importance of identifying synergies between violence prevention and health platforms. Thus, integrated care in communitybased settings including schools, families, and health services should be supported based on a previously defined national strategy. Social workers, peer educators, and other health professionals who used to be involved in school settings and health facilities will be key elements to promote this approach. At the community level, increasing the awareness of connection between depressive symptoms and violence, even among those usually accepted as normal for this age group, is essential. Campaigns should be developed and implemented to increase the perception of the problem on the community, which will have an impact on the individuals' behaviors, particularly on the disclosure of the problem. At school level, an intervention strategy should be implemented to provide a response if there is reason to suspect the existence of the problem, namely to refer the student to the appropriate social and health service.

Social work professionals may have a relevant role in the approach to both social and health problems because they have a holistic understanding of these issues (Bowen \& Walton, 2015). Social workers are the ideal mediators for this model of mental health that integrates schools, families, and health facilities. They may have a relevant role because they are able to be in contact with students and families within the school setting and are prepared to lead a multidisciplinary team in program planning and implementation. They should be involved in programs that provide early mental health screenings for school children and adolescents, and also in developing a community approach to aid students with difficulties before they feel the need to act out in violence. Thus, it would be important for schools and parents to be aware of mental health issues that may be common during adolescence.

\section{Conclusion}

Depressive symptoms were associated with physical fighting involvement during adolescence, in both genders. However, whereas in female adolescents the association was significant when relevant symptoms and fighting occurred in the same period, in male adolescents such symptoms persisted from age 13 to age 17 . Being attentive to depressive symptoms among adolescents may prevent disease progression and have potential effects on the prevention of violent behavior in adolescence. HSW

\section{REFERENCES}

Anderson, M., Kaufman, J., Simon, T. R., Barrios, L., Paulozzi, L., Ryan, G., et al. (2001). School-associated violent deaths in the United States, 1994-1999. JAMA, 286, 2695-2702.

Araujo, J., Severo, M., \& Ramos, E. (2012). Sleep duration and adiposity during adolescence. Pediatrics, 130(5), e1146-e1154. doi:10.1542/peds.2011-1116

Beck, A. T., Steer, R. A., \& Brown, G. K. (1996). Manual for the Beck Depression Inventory II. San Antonio, TX: Psychological Corporation.

Belfrage, H., \& Rying, M. (2004). Characteristics of spousal homicide perpetrators: A study of all cases of spousal homicide in Sweden 1990-1999. Criminal Behaviour and Mental Health, 14(2), 121-133.

Bland, R., \& Orn, H. (1986). Family violence and psychiatric disorder. Canadian Journal of Psychiatry, 31(2), 129-137.

Borowsky, I. W., \& Ireland, M. (2004). Predictors of future fight-related injury among adolescents. Pediatrics, 113, 530-536.

Bowen, E. A., \& Walton, Q. L. (2015). Disparities and the social determinants of mental health and addictions: Opportunities for a multifaceted social work response. Health \& Social Work, 40, e59-e65. doi:10.1093/hsw/ hlv034

Bulhoes, C., Ramos, E., Lindert, J., Dias, S., \& Barros, H. (2013). Depressive symptoms and its associated factors in 13-year-old urban adolescents. International Journal of Environmental Research and Public Health, 10, 5026-5038. doi:10.3390/ijerph10105026

Centers for Disease Control and Prevention. (1992). Physical fighting among high school students-United States, 1990. Morbidity and Mortality Weekly Report, 41(6), 91-94.

Chester, K. L., Callaghan, M., Cosma, A., Donnelly, P., Craig, W., Walsh, S., \& Molcho, M. (2015). Cross-national time trends in bullying victimization in 33 countries among children aged 11, 13 and 15 from 2002 to 2010. European Journal of Public Health, 25(Suppl. 2), 61-64. doi:10.1093/ eurpub/ckv029

Cleary, S. D. (2000). Adolescent victimization and associated suicidal and violent behaviours. Adolescence, 35, 671-682.

Coelho, R., Martins, A., \& Barros, H. (2002). Clinical profiles relating gender and depressive symptoms among adolescents ascertained by the Beck Depression Inventory II. European Psychiatry, 17, 222-226.

Colder, C. R., Scalco, M., Trucco, E. M., Read, J. P., Lengua, L. J., Wieczorek, W. F., \& Hawk, L. W., Jr. (2013). Prospective associations of internalizing and externalizing problems and their co-occurrence with early adolescent substance use. Journal of Abnormal Child Psychology, 41, 667-677. doi:10.1007/s10802012-9701-0

Cosgrove, V. E., Rhee, S. H., Gelhorn, H. L., Boeldt, D., Corley, R. C., Ehringer, M. A., et al. (2011). Structure and etiology of co-occurring internalizing and externalizing disorders in adolescents. Journal of Abnormal Child Psychology, 39, 109-123. doi:10.1007/s10802010-9444-8

Costello, E. J., Mustillo, S., Erkanli, A., Keeler, G., \& Angold, A. (2003). Prevalence and development of psychiatric disorders in childhood and adolescence. Archives of General Psychiatry, 60, 837-844. doi:10 .1001 /archpsyc.60.8.837 
Dutton, D. G., \& Karakanta, C. (2013). Depression as a risk marker for aggression: A critical review. Aggression and Violent Behavior, 18, 310-319.

Fazel, S., Wolf, A., Chang, Z., Larsson, H., Goodwin, G. M., \& Lichtenstein, P. (2015). Depression and violence: A Swedish population study. Lancet Psychiatry, 2(3), 224-232. doi:10.1016/s2215-0366(14)00128-x

Fraga, S., Ramos, E., Dias, S., \& Barros, H. (2011). Physical fighting among school-going Portuguese adolescents: Social and behavioural correlates. Preventive Medicine, 52, 401-404. doi:10.1016/j.ypmed.2011.02.015

Kim, H. K., \& Capaldi, D. M. (2004). The association of antisocial behavior and depressive symptoms between partners and risk for aggression in romantic relationships. Journal of Family Psychology, 18(1), 82-96. doi:10.1037/0893-3200.18.1.82

Nestor, P. G. (2002). Mental disorder and violence: Personality dimensions and clinical features. American Journal of Psychiatry, 159, 1973-1978. doi:10.1176/appi.ajp .159.12.1973

Patten, C. A., Choi, W. S., Vickers, K. S., \& Pierce, J. P. (2001). Persistence of depressive symptoms in adolescents. Neuropsychopharmacology, 25(Suppl. 5), S89-S91. doi:10.1016/s0893-133x(01)00323-2

Pickett, W., Craig, W., Harel, Y., Cunningham, J., Simpson, K., Molcho, M., et al. (2005). Cross-national study of fighting and weapon carrying as determinants of adolescent injury. Pediatrics, 116, e855-e863.

Pickett, W., Molcho, M., Elgar, F. J., Brooks, F., de Looze, M., Rathmann, K., et al. (2013). Trends and socioeconomic correlates of adolescent physical fighting in 30 countries. Pediatrics, 131, e18-e26. doi:10.1542/ peds.2012-1614

Ramos, E., \& Barros, H. (2007). Family and school determinants of overweight in 13-year-old Portuguese adolescents. Acta Paediatrica, 96, 281-286.

Renouf, A. G., \& Harter, S. (1990). Low self-worth and anger as components of the depressive experience in young adolescents. Development and Psychopathology, 2, 293-310.

Roland, E. (2002). Aggression, depression and bullying others. Aggressive Behavior, 28(3), 198-206.

Waite, R. L. (2006). Variations in the experiences and expressions of depression among ethnic minorities. Journal of National Black Nurses' Association, 17(1), 29-35.

Wang, Y. P., Lederman, L. P., Andrade, L. H., \& Gorenstein, C. (2008). Symptomatic expression of depression among Jewish adolescents: Effects of gender and age. Social Psychiatry and Psychiatric Epidemiology, 43(1), 79-86. doi:10.1007/s00127-007-0270-4

Zuravin, S. J. (1989). Severity of maternal depression and three types of mother-to-child aggression. American Journal of Orthopsychiatry, 59, 377-389.

Silvia Fraga, PhD, is postdoc researcher, Social Epidemiology Group, EPIUnit, Instituto de Saúde Pública da Universidade do Porto, Rua das Taipas 135/139, Porto, 4050-600 Portugal; e-mail: silfraga@med.up.pt. Elisabete Ramos, PhD, is assistant professor and Henrique Barros, PhD, is professor, Faculdade de Medicina da Universidade do Porto, Portugal. Both are also researchers, EPIUnit, Instituto de Saúde Pública da Universidade do Porto.

Original manuscript received June 23, 2016

Final revision received August 4, 2016

Editorial decision August 5, 2016

Accepted August 8, 2016

Advance Access Publication March 9, 2017 